\title{
A meta-analysis of COVID-19: Challenging Australias' vocational education sector
}

\author{
Matthew Pearson* \\ University of Central Queensland; Faculty of Health Medical and Applied Sciences, College of \\ Science and Sustainability; Mackay- Ooralea Campus \\ *Corresponding author, e-mail: m.w.pearson@cqu.edu.au
}

\begin{abstract}
With the advent of the digital age, vocational education and associated policy documents can create an awkward marriage for the student and educator. For the student, the move to an online platform of learning containing digital tools is more than just mastery of a program but requires support, to resolve the financial costs and connectivity issues associated with learning in isolation. For the educator, online platforms provide a challenge not only will they became a student to learn the new platform. The educator confronted with new or unfamiliar pedagogical practices vastly different from their past learning experiences. However, the digital divide is complexing with no one issue attributing or resolving the digital divide.
\end{abstract}

Keywords: vocational education, digital, learning

How to Cite: Pearson. M. (2020). A meta-analysis of COVID-19: Challenging Australias' vocational education sector. Journal of Vocational Education Studies, 3(2), 53-62. DOI: https://doi.org/10.12928/joves.v3i2.2547.

\section{INTRODUCTION}

The digital divide is not new, nor is it uniquely Australian, but from COVID-19 has brought the divide to the forefront of education. The Australian media has reported the impact of the digital divide in compulsory years of schooling (Capel-Stanley, 2020; Li \& Lalani, 2020; Visentin, 2020). The attention afforded to compulsory years of schooling questions the implications for vocational education. Defining the digital divide as internet access is restrictive, and forgets the associated technologies, i.e. mobile communication devices and associated technological infrastructure. In the media, a survey conducted by the NSW Council of Social Services found 15\% could not afford the internet or voice calls, and a further 29\% had limited technological availability due to financial stress (Visentin, 2020). The use of digital tools has steadily increased since 2008 (Thomas, Wilson, \& Park, 2020). An ABS survey defined those who would be digitally disadvantaged includes rural and remote communities (Thomas et al., 2020). From the ABS, the uptake of online banking or social networking has been the main areas of growth with accessing education, having a smaller but consistent growth (Thomas et al., 2020). Thomas et al. (2020) showed that online engagement in all facets of society is becoming increasingly reliant on online technologies.

The NSW Council of Social Services reported that working from home and communicating online has created considerable economic hardship on households (Visentin, 2020). Visentin (2020) describes that students who return home from postcompulsory education have two immediate issues to resolve inadequate digital access due to redundant technology or poor connectivity. Maintaining a connection with postcompulsory education has seen the use of public libraries increase as an avenue to maintain connectivity (Capel-Stanley, 2020). Capel-Stanley (2020) describes that the cost of technology can be prohibitive for the students without a means of support. Hence, public libraries provide open space with connectivity and other resources. 
COVID-19 has challenged the social norms found in society, but the digital revolution in education was occurring before the pandemic (Li \& Lalani, 2020). Li and Lalani (2020) reported that tech companies were already developing educational software for the compulsory years of schooling. Li and Lalani (2020) interview with one tech company described how the learning was changing from solely classroom-based to that of a blended delivery by using online technologies. From Li and Lalani (2020) a comparison between online education and traditional classroom; students who use an online environment can retain between $25-60 \%$ of material compared to the classroom environment where only $8-10 \%$ of material retained. Li and Lalani (2020) explained that the differences were due to how online learners can customise the learning and the learning environment to their needs.

Li and Lalani (2020) exposé on digital learning did come with the acknowledgement that a digital divide did exist in Australia. Li and Lalani (2020) recognised that state governments had created intervention programs to assist households to cross the digital divide. Government intervention did not occur just for equity reason, but as Russo (2020) and Campbell (2020) describes as a recognition to the changes in work in a digital age.

\section{Policy and the digital divide}

Educational policy and the digital divide can represent a policy conundrum in the postcompulsory education sectors. The difficulties faced in the sector is a mixture of economic and social costs of using the technology. An underlying assumption which challenges the use of digital tools is questioning their effectiveness for teaching and learning (Johnson, Macdonald, \& Brabazon, 2008). Platforms that support the use of e-learning have become incredibly elaborate with several digital tools available for educators and students (Johnson et al., 2008). Johnson et al. (2008) discuss the use of digital tools does not necessarily lead to improved learning outcomes. Several issues restrict the learning process for students ranging from the infrastructure to support the use of digital tools (Johnson et al., 2008). The digital divide for Registered Training Organisations is not explicitly addressed either within the assessment or equity policies. Addressing the digital divide through policy is no easy matter as the use of digital tools is an evolving area. Johnson et al. (2008) identify the impact of the digital divide can restrict access to the learning materials but can restrict assessment to gauge the learning which has occurred. Assessment in Registered Training Organisation follows the User Guide to the Standard for Registered Training Organisation (Paterson, 2019). The Standards (Paterson, 2019), are effectively a policy document for Registered Training Providers, particularly Standard 1.8, on assessment. Standard 1.8 would be reflective of the assessment principles and the rules of evidence which Registered Training Organisations would use. In Paterson (2019), there is no indication to indicate how digital tools can apply to the learning environment explicitly. Instead, Paterson (2019), provides several principles required for developing assessments.

The challenge identified by Backroad Connections Pty Ltd (2002) in the policy framework is to determine if the assessment is authentic and original. The concept of authentic assessment is one of the principles identified by Paterson (2019) when designing assessments. Backroad Connections Pty Ltd (2002) identified similar barriers to Johnson et al. (2008) regarding technological availability and support. An incorrect assumption which Registered Training Organisation could make is assuming students are technological natives when they may be technological immigrants based on the term used by Waycott, Bennett, Kennedy, Dalgarno, and Gray (2010). The discussion on the application of digital technologies to assessment may not occur, but the trigger used by Paterson (2019) is from raising question on equity in assessment. The aspect of equity, as discussed by Willems (2001), is not solely about the students, but includes the educator. The aspect of introducing 
technology, as discussed by Willems (2001) need to take into consideration the needs and abilities of the students and educators to avoid creating a digital divide in the learning environment.

\section{Society and the divide}

The digital divide found in Australian society described by Visentin (2020) is reflective and characteristic of the digital divide found elsewhere in the world. Change in education has layers of complexity related to many factors in society factors (Campbell, 2020). Campbell (2020) discusses that multiculturism and technology can be related to exposure to technological. Hannum and Buchmann (2005) explain the digital tools, and personal investment (exposure) can be a limitation to digital acceptance. Technology and education, according to Hannum and Buchmann (2005), may reflect a person level of adaption towards technology. Hannum and Buchmann (2005) conclude by describing how technology can be a mechanism for advancing national skills. Reaffirming Hannum and Buchmann (2005) point was through an article by Russo (2020) where government intervention to reduce the digital divide in education is necessary as part of preparing a digitally literate workforce for the future. Education and the digital divide as Hannum and Buchmann (2005) discuss can have a national economic impact.

Waycott et al. (2010) apply the terms digital native and digital immigrant these can be restrictive for defining the issue. Kapitzke (2000) identified the same problems when trying to categories the digital immigrant. Waycott et al. (2010) explained the digital native is a student born in the age of technological innovation. Compared to the digital immigrant or the teacher was born outside this period (Waycott et al., 2010). Waycott et al. (2010) explanation contain several assumptions that might not reflect online learning. The first is the digital native birth occurred in the 1990s, which means mature age students who were born earlier are perceived to be digital natives. A reversal can occur where the teacher was born in the 1990s will be a digital immigrant. Waycott et al. (2010) acknowledge an age boundary can add an unnecessary complication to understanding the digital divide in Australia.

Waycott et al. (2010) investigation focused on how students and teachers interacted with the technology. The crux of Waycott et al. (2010) investigation is the value of technology in an educational environment. Waycott et al. (2010) indicate that digital natives and immigrants are discerning users of technology and need to see value in the technology before accepting and using technology. Waycott et al. (2010) described how digital natives and immigrants saw living with digital technology can become a distraction to education. The critical aspect Waycott et al. (2010) identified is the value or importance of technology towards meeting an educational goal. Interviews conducted by Waycott et al. (2010), neither the digital natives nor immigrants described the application of Web 2.0 technologies. The definition of Web 2.0. tools or digital tools are blogs, or podcasts or wikis as part of e-learning (Mohammadyari \& Singh, 2015; Waycott et al., 2010). Waycott et al. (2010), identified the absence of emerging technologies has links to the article by Russo (2020), discussing digital literacy and skills of the future.

Australia, as a multicultural society our historical past can reflect a variety of geopolitical pathways which COV-19 has brought to the forefront. Bozkurt et al. (2020) describe a person background through migration reflects exposure to digital technology or access to digital technology. The problems from the digital divide can create issues relating to social justice (Bozkurt et al., 2020). The area of social justice and social connectedness through various support mechanism is overcoming some of the new education hurdles that COVIS-19 is creating (Carver, 2020). The lack of social connectedness that can come from a digital learning environment can relate to isolation as defined by Vega and Brennan (2000).

Volume 3, Number 2, November 2020 
The type of digital technology available in Vega and Brennan (2000) investigation was before the advent of digital multimedia, i.e. live streaming from the use of a digital camera.

Nevertheless, the Vega and Brennan (2000) concept of isolation would still be applicable, as, not all learning is live streaming. Vega and Brennan (2000) made the point the barriers of communication and access to information have reduced; this has come at the expense of personal privacy. Vega and Brennan (2000) view of digital technology provides an alternative to the digital divide separating due to an inability to participate in that of creating social division through the loss of privacy from digital technology.

\section{RESULTS AND DISCUSSION \\ Vocational Education Policy Development}

Post compulsory education policy is considered by Abbott-Chapman (2011) as involving several complex hierarchies which have vertical and horizontal stratification. AbbottChapman (2011) description of the complexities involved in post-compulsory education places the vocational education in competition with higher education. Understanding the relationship between vocational education and higher education can result in understanding how to address low socioeconomic status. Low socioeconomic status does not necessarily contribute to the digital divide but can be associated with the digital divide. However, from Abbott-Chapman (2011), an insight into possible reasoning as to why a digital divide may exist in low socioeconomic status is provided. Government policy supports rural, regional and remote areas including areas of low socioeconomic status to have access to post-compulsory education (Abbott-Chapman, 2011). Abbott-Chapman (2011) defines low socioeconomic families tend to view favourably post-compulsory education options as those delivered locally with tangible employment outcomes, i.e. vocational education" trade" programs.

Governments subsidise the delivery of "trade" programs to meet employment demands (Abbott-Chapman, 2011; Gekara, Snell, Molla, Karanasios, \& Thomas, 2019). The Government's investment in "trade" relates to science, technology engineering and mathematics as part of jobs of the future (Gekara et al., 2019). The concern identified by Gekara et al. (2019) in these programs are not meeting the employer's needs. Digital literacy is given a low status in the packaging rules for technical/trade areas (Gekara et al., 2019). Abbott-Chapman (2011) explains that vocational training delivers practical employment training through designing learning like a job and person specification. The inclusion of digital literacy occurs in some units of competency but is not taught explicitly (Gekara et al., 2019).

\section{Historical Perspectives}

The evolution of digital tools in the workplace reflects the growing reliance on digital tools (Willis \& Tranter, 2016). The use of digital tools within the workplace is not new but is reflective of the evolution of the industrial revolution (Verawardina et al., 2020). The later version of the industrial revolution as described by (Verawardina et al., 2020) reflects the growth in automation and artificial intelligence. As industries have evolved, so has online learning at home becoming increasingly flexible and innovative (Verawardina et al., 2020). Access to digital tools has been reflective of the household income and level of education in the opinion of Willis and Tranter (2016). Australia is not alone with the provision of digital technologies within the home. The problems of access and reliability of digital technology were common in overseas countries (Bozkurt et al., 2020). Bozkurt et al. (2020) attributed the problems of digital technology and the divide it can create to that of household income.

Willis and Tranter (2016) identified that age was a critical factor in how people interacted with digital tools. Willis and Tranter (2016) argument on age is reflective of 
Waycott et al. (2010) who categorised the digital divided into digital natives and the digital immigrants based on age. Unlike Waycott et al. (2010) which used categories to understand the digital divide location was an equally important aspect to the divide, particularly in Australia. Willis and Tranter (2016) describe digital usage differed between the city and country users. Country users were behind in the use of digital technologies compared to city users (Willis \& Tranter, 2016). Young, Robertson, Sawyer, and Guenther (2005) reaffirms Willis and Tranter (2016) perspective on the difficulties of accessing and maintaining digital connectivity in rural/remotes areas.

The spatial difficulties associated with e-learning from Willis and Tranter (2016) only partly addresses a historical legacy of vocational education. A legacy rarely addressed in vocational education is the training of vocational educators. The description of the digital divide by Abbott-Chapman (2011), where rural/regional communities view postcompulsory education as needing to occur locally, tends to reinforce the rural/regional digital divide. Vocational educators located in the digital divide would be as Waycott et al. (2010) describes digital immigrants. Becoming a vocational educator, unlike compulsory education where a University degree and registration is required, there is no individual registration for a vocational educator. Instead, the educational requirements are a Certificate IV qualification as per the national vocational education framework in Australia (Paterson, 2019; Robertson, 2014). The perception given to a vocational educator under the framework requires registration, but the registration is for the training organisation only (Paterson, 2019; Robertson, 2014). The evolution of a vocational educator is a person moving from a "trade" role to training and assessing role (Robertson, 2014). Robertson (2014) describes a vocational educator in the 1970s to the mid-1980s trained with pedagogical knowledge as part of a teaching diploma. Evolution of the vocational education system meant industry knowledge and practices become increasingly important rather than pedagogical knowledge (Robertson, 2014). Robertson (2014) vocational educator description supports Abbott-Chapman (2011) as their trained to deliver workplace training within an industry context, which means the training practices are reflective of the training that they received (Robertson, 2014).

Those involved in VET delivery need to juggle the requirements of two roles being the vocational education sector and role from the industry reflective of "trade" background (Kemmis, Hodge, \& Bowden, 2014). Vocational Educators need to maintain the skills in vocational education and the skills of the training package that they would delivery (Kemmis et al., 2014; Paterson, 2019). An area of weakness that has been identified in the Australian VET sector by (Kemmis et al., 2014) is the lack of transferability of skills from vocational education to industry maintain relevancy to the training package. The concept of transferability further developed by having transferable skills enshrined in the units of competency (Kemmis et al., 2014). Vocational Educators focus on meeting the requirements set by a training regulatory body but have an emerging area of in education may become overlooked in favour of meeting industry demand. Carver (2020) discusses how the move from face to face teaching and challenging traditional educational delivery models through the emergence of the COVID-19 pandemic. COVID-19 moved the focus from teaching in a classroom or workshop to that of an online platform. Consequently, the process of teaching, learning and assessing had to be redesigned for placement onto an online learning platform (Carver, 2020).

\section{COVID-19 and Learning Environment}

The adaption of the moving from classroom to blended to entire exclusively online learning can create challenges for students, educators and instructional designers. Vocational education in the Australian context is about tactile learning supplemented through learning job task knowledge (Paterson, 2019). Verawardina et al. (2020) describe e-learning as a 
means to supplement knowledge which would otherwise occur in the classroom. E-learning lends itself to a constructionism framework due to the students need to contextualise the knowledge to their environment (Verawardina et al., 2020). The process of converting the traditional vocational learning environment to an e-learning environment needs to consider the content and the outcomes required to gain competency in the unit. The process of gaining competency in a unit through e-learning can change and challenge the role of the educator. In an e-learning environment, as Kaur (2020) points out other sources of information and delivery systems can complete against the e-learning platform selected by the educator. Kaur (2020) described that the learning environment needs to assimilate the educators learning platform but also those resources external to the educators' platform. The inclusion of external resources can affect the effectiveness and efficiency of the learning, but students will require the ability to collaborate in the design of the learning environment (Kaur, 2020).

Creating an e-learning environment is to facilitate the students learning is only partly addresses the role of the educator, including resources from external sites and encouraging student participation. The educator still needs to gauge the learning that has occurred. Kaur (2020) describes the use of online assessment tools seen as an evolution of the assessment tools used in the classroom. The change in assessment practices can be mean a change in learning practices used by the students (Bozkurt et al., 2020). Educators are challenged from the to convert previous classroom assessment tools to an online assessment tool (Bozkurt et al., 2020). Online assessment tools need to be considerate of the learners but also needs to take into consideration the academic integrity issues associated with an online environment.

\section{Addressing the digital divide in vocational educational}

The nexus between technology and vocational education can have historical routes with the industrialisation of society (Verawardina et al., 2020). As society developed and the economies have matured the need for advancement in the industry has followed suit. The industrial revolution saw the start of the introduction of the technology, and over time the industrial revolution has evolved to reflect the current use of digital technology in advanced manufacturing practices (Verawardina et al., 2020).

The impact of COVID-19 brought the digital divide to the forefront of media (Campbell, 2020; Russo, 2020). The common theme in the articles is a city-centric bias. In the regional and remote parts of Australia, the digital divide is a common everyday occurrence (Young et al., 2005). Even though regional and remote communities have access to digital tools, digital literacy and support were two critical limiting factors, according to Young et al. (2005). Young et al. (2005) identified digital tools for e-learning lack support to encourage members of the community to use these tools. The investigation by Young et al. (2005) identified a lack of support for post-compulsory education was constraining community development. Young et al. (2005) delivery of vocational education has enabled these communities to establish their identity through art or numeracy/literacy programs. Young et al. (2005) acknowledge the delivery of low Australian Qualification Framework vocational units can hamper the full development of these communities. Reduced educational engagement can correlate to a lack of digital support for these communities.

During, COVID-19 media coverage of vocational education, has not been predominant. Compared to the compulsory schooling and higher education. From the higher education sector, several vital messages can apply equally to vocational education. Murgatroyd (2020) reviews the impact and opportunities facing higher education. Murgatroyd (2020) acknowledges that e-learning may not be a core business component of higher education but post COVID-19 e-learning will be a fundamental of the education 
sector to offer flexibility and education on-demand. Murgatroyd (2020) foreshadows further rationalisation will occur in education where programs that were once delivered may not occur due to the economics post-COVID-19. The impact of rationalisation can widen the digital divide (Young et al., 2005). Moving educational programs to an online platform may reduce student participation (Young et al., 2005). The problem identified by Murgatroyd (2020) is that educators and students may not be technologically savvy to navigate an e-learning platform.

The digital-savvy may like a vague, as Carver (2020) describes problems which COVID-19 has created for educators in transgressing to a digital platform involves a component of panic. The term that Carver (2020) used for transgressing the to a digital platform to meet the policy demands of Government is that of panicgogy a hybridisation of panic and pedagogy. The cause of the panicgogy as Murgatroyd (2020), Young et al. (2005), and Russo (2020) identified was the lacking in digital literacy skills in either the cities or regional areas. Russo (2020) describes addressing digital literacy through direct intervention rather than natural learning, i.e. learning ITC in a haphazard and at needs approach. Russo (2020) not alone in identifying poor digital literacy, as Murgatroyd (2020) described the need for educational institutions to enable students to become digital-savvy.

\section{CONCLUSIONS}

The digital divide is not traditional, nor can it be easily categorised. COVID-19 has shone a light on the application of digital tools in society. Many of the underlying aspects of the digital divide relate to traditional areas where disengages occur, i.e. city-country divide, low incomes, multiculturism. New areas are contributing to the divide being exposure/acceptance of new technology to change processes. The digital divide can equally challenge some social theorist due to the complexity which can occur, i.e. a rich person in the country can be just as disadvantaged as a poor person in the city. Vocational education can lead by scaffolding the learning to cross the divide, but government assistance is still required.

\section{REFERENCES}

Abbott-Chapman, J. (2011). Making the most of the mosaic: facilitating post-school transitions to higher education of disadvantaged students. The Australian Educational Researcher, 38(1), 57-71. doi:10.1007/s13384-010-0001-9

Backroad Connections Pty Ltd. (2002). Assessment and Online Teaching. Retrieved from Melbourne: http://flexiblelearning.net.au/guides/assessment.html.

Bozkurt, A., Jung, I., Xiao, J., Vladimirschi, V., Schuwer, R., Egorov, G., . . Paskevicius, M. (2020). A global outlook to the interruption of education due to COVID-19 Pandemic: Navigating in a time of uncertainty and crisis. Asian Journal of Distance Education, 15(1), 1 - 126.

Campbell, C. (2020, 8 April). SA schools' online learning set-ups to highlight internet and technology access disparities. $A B C$ News.

Capel-Stanley, C. (2020, April 22nd). Library coronavirus lockdown cuts off disadvantaged Australians from the digital world. The Guardian.

Carver, L. B. (2020). Supporting Learners in a Time of Crisis. Advances in Social Sciences Research Journal, 7(4), 129-136. doi:10.14738/assrj.74.8109

Gekara, V., Snell, D., Molla, A., Karanasios, S., \& Thomas, A. (2019). Skilling the Australian workforce for the digital economy. Adelaide: NCVER

Hannum, E., \& Buchmann, C. (2005). Global Educational Expansion and Socio-Economic Development: An Assessment of Findings from the Social Sciences. World Development, 33(3), 333-354. doi:10.1016/j.worlddev.2004.10.001

Johnson, N. F., Macdonald, D., \& Brabazon, T. (2008). Rage against the Machine? Symbolic Violence in E-Learning Supported Tertiary Education. E-Learning and Digital Media, 
5(3), 275-283. doi:10.2304/elea.2008.5.3.275

Kapitzke, C. (2000). Information Technology as Cultural Capital: Shifting the Boundaries of Power. Education and Information Technologies, 5(1), 49 - 62.

Kaur, G. (2020). Digital Life: boon or bane in teaching sector on covid -19. CLIO An Annual Interdisciplinary Journal of History, 6(6), 216 - 427.

Kemmis, R. B., Hodge, S., \& Bowden, A. (2014). Transferable skills in Technical and Vocational Education and Training (TVET): Implications for TVET teacher policies in Australia.TVET@Asia, 3, 1 - 13.

Li, C., \& Lalani, F. (2020). The COVID-19 pandemic has changed education forever. This is how.

Mohammadyari, S., \& Singh, H. (2015). Understanding the effect of e-learning on individual performance: The role of digital literacy. Computers \& Education, 82, 11-25. doi:10.1016/j.compedu.2014.10.025

Murgatroyd, S. (2020). A Cancelled Future: What's Next for Universities and Colleges? Strategic Foresight for Educational Leaders, 7(9), 1 - 17.

Paterson, M. (2019). Users' guide to the Standards for Registered Training Organisations (RTOs) 2015. Melbourne (Australia): Australian Skills Quality Authority

Robertson, I. (2014). VET Teachers' Knowledge and Expertise. International Journal of Training Research, 6(1), 1-22. doi:10.5172/ijtr.6.1.1

Russo, K. (2020, April 30th). Online classes will help prepare kids for future. The Mirage News.

Thomas, J., Wilson, C. K., \& Park, S. (2020, March 29th). Australia's digital divide is not going away. The Conversation.

Vega, G., \& Brennan, L. (2000). Isolation and technology: the human disconnect. Journal of Organizational Change Management, 13(5), 468 - 481.

Verawardina, U., Asnur, L., Lubis, A. L., Hendriyani, Y., Ramadhani, D., Dewi, I. P., . . . Sriwahyuni, T. (2020). Reviewing Online Learning Facing the Covid-19 Outbreak. Talent Development \& Excellence, 12(3S), 385 - 392.

Visentin, L. (2020, April 17th ). 'Digital divide': lower income households struggle with internet access, Coronavirus Pandemic. The Sydney Morning Herald.

Waycott, J., Bennett, S., Kennedy, G., Dalgarno, B., \& Gray, K. (2010). Digital divides? Student and staff perceptions of information and communication technologies. Computers \& Education, 54(4), 1202-1211. doi:10.1016/j.compedu.2009.11.006

Willems, J. (2001). Equity: A key benchmark for students and staff in an era of changing demands, changing directions. Paper presented at the ASCILITE Conference: Changing demands, changing directions, Hobart.

Willis, S., \& Tranter, B. (2016). Beyond the 'digital divide'. Journal of Sociology, 42(1), 43-59. doi: $10.1177 / 1440783306061352$

Young, M., Robertson, P., Sawyer, G., \& Guenther, J. (2005). Desert disconnections: e-learning and remote Indigenous peoples. Retrieved from Brisbane: flexiblelearning.net.au. 